\title{
SELECTIVE FLOTATION OF FOSSIL RESIN FROM WESTERN COAL
}

\author{
DOE Contract DE-AC22-90PC90178
}

Quarterly Report for August 31, 1991 to November 30,1991

\author{
Submitted by: $\quad$ Gordon F. Jensen, Director \\ Utah Engineering Experimental Station \\ University of Utah \\ Salt Lake City, Utah 84112
}

and

Jan D. Miller, Professor

Department of Metallurgical Engineering

University of Utah

Salt Lake City, Utah 84112

March 30,1992

\section{DISCLAIMER}

This report was prepared as an account of work sponsored by an agency of the United States This report was prepared as an account of work sponsored by anency thereof, nor any of their employees, makes any warranty, express or implied, or assumes any legal liability or responsibility for the accuracy, completeness, or usefulness of any information, apparatus, product, or process disclosed, or represents that its use would not infringe privately owned rights. Reference herein to any specific commercial product, process, or service by trade name, trademark, manufacturer, or otherwise dces not isecessarily constitute or imply its endorsement, recommanufacturer, or otherwise dces not inecessarily constitute or imply its endorsementere the views mendation, or favoring by the United States Government or any agency thereof. The views
and opinions of authors expressed herein do not necessarily state or reflect those of the United States Government or any agency thereof. 
Technical activities for the fifth quarter of DOE contract. DE-AC22-90PC90178, "Selective Flotation of Fossil Resin from Western Coal," mainly involved efforts on economic analysis conducted by both the University of Utah and Advanced Processing Technologies, Inc.

Economic analysis of this fossil resin project mainly focused on the flotation plant which is intended to be designed with data obtained from the current proof-of-concept flotation test program. It is believed that the analysis of this step is fairly accurate. The other two economic aspects of fossil resin recovery/utilization are refining and marketing. Cost data used for refining were from an estimated base and are believed to have a relatively large variance. Marketing data used were obtained from two independent marketing studies which were made available on confidentiality basis. Nevertheless, the data used are believed to be fairly accurate with respect. to the market potential.

The scenario involved in this economic analysis is that an existing coal preparation plant is available and is retro-fitted to establish the fossil resin flotation plant. The refining plant will have to be constructed almost as a greenfield site. The flotation plant is engineered for the production of 20 million pounds of fossil resin per year (referred to as Phase I) while the refining plant has a capacity to process 48 million pounds of fossil resin per year. In this way, future expansion can easily be accomplished by adding another flotation plant at the location of another coal mine (referred as phase II). 


\section{TOTAL CAPITAL COST}

\section{A) Flotation Plant Capital Cost (Phase I)}

The principle assumption for the flotation plant capital costs involved in the Phase I period is that an existing, decommissioned coal processing plant is available and is retro-fitted with the fossil resin flotation plant.

Capital Cost

1. Utilities Conversion

2. Plant Feed Systems

3. Flotation Preparation

4. Coarse Coal Handling

5. Mid Size Coal Handling

6. Fine Size Coal Handling

7. Processed Coal Shipping

8. Water Systems

9. Resin Flotation

10. Fine Coal Processing

11. Resin Filtration

12. Lime Circuit
$\$ 350,000$

$\$ 47,000$

$\$ 62,000$

$\$ 50,000$

$\$ 50,000$

$\$ 120,000$

$\$ 50,000$

$\$ 20,000$

$\$ 140,000$

$\$ 390,000$

$\$ 80,000$

$\$ 50,000$

Subtotal

$\$ 1,409,000$

$\$ 150,000$

$\$ 150,000$

$\$ 300,000$

Subtotal

$\$ 600,000$

Other Cost

Purchase Old Plant

Land \& Access

$\$ 800,000$

Subtotal

$\$ 800,000$

TOTAL

$\$ 2,809,000$ 


\section{B) Resin Refining Plant Cost}

The principle assumption for THE resin refining plant capital costs is that the land is already available from foregoing purchase of an old coal processing plant. The entire plant has yet to be constructed and will be constructed adjacent to the resin flotation plant. Preliminary analysis as well as the information obtained from independent sources indicate that there is little difference in capital cost between constructing a 20 million pound per annum refining plant and a 48 million pound per annum refining plant since this is a very small refining plant. In this way, a 48 million pound capacity was chosen for the purpose of future expansion (installation of resin flotation plant at other sites. For a 48 million pounds resin refining plant (about 22,000 metric tons per year). The estimated capital cost is about $\$ 3,000,000$ with a variance of plus and minus $\$ 500,000$.

C) Operating Capital

The estimated yearly operating capital for both flotation and refining plant is about $\$ 3,551,000$ as demonstrated in the total yearly operating capital cos $₫$ balance sheet. The first year's operating capital has to be funded as a capital investment. It is assumed that the operating capital for the second year can be generated from the first years sales.

D) Summary of Capital Cost

Details for the capital cost estimates will be provided in the final report. Consideration of all capital outlay shows that the grand total for capital cost should be $\$ 9,359,000$ 


\section{TOTAL PHASE I YEARLY OPERATION COST}

A) Flotation Plant

Labor

Foreman (1)

Lead Operators (4)

Operators (4)

Reagent

Power and Other Utilities

Transportation

TOTAL YEARLY OPERATING COST resin Produced)

Base

(\$/year)

55,000

32,000

28,000
Labor Subtotal
$\$ 34,000$

$\$ 200,000$

$\$ 400,000$

$\$ 921,000$ (Equivalent to $\$ 0.0460 / \mathrm{lb}$

$\$ 55,000$

$\$ 120,000$

$\$ 112,000$

$\$ 287,000$

B) Refining Plant

Again, unlike the flotation plant, the costs for refining (both capital and operating) are rough estimates. In this regard, it is believed that the operating cost will be about $\$ 750,000 /$ annum, which is equivalent to $\$ 0.0375 / \mathrm{b}$ of resin produced, since the refining plant is on such a small scale. 
C) Total Yearly Operating Cost and Income

\begin{tabular}{lcc}
\multicolumn{1}{c}{ Source } & Amount & \$1b \\
U of U Patent Royalty & $\$ 80,000$ & 0.0040 \\
Resource Payments & $\$ 400,000$ & 0.0200 \\
Flotation Plant & $\$ 921,000$ & 0.0460 \\
Refining Plant & $\$ 750,000$ & 0.0375 \\
Administration/Overhead & $\$ 400,000$ & 0.0200 \\
Sales Cost & $\$ 600,000$ & 0.0300 \\
Management & $\$ 400,000$ & 0.0200 \\
\multicolumn{1}{c}{ Subtotal } & $\$ 3,551,000$ & 0.1778 \\
& & \\
Sinking Fund Payment & $\$ 1,484,317$ & 0.0742 \\
Total Expense Before Tax & $\$ 5,035,317$ & 0.2518 \\
& & \\
& & \\
Income (Sales) & $\$ 10,000,000$ & 0.5000 \\
& & \\
Net Income Before Tax & $\$ 4,964,683$ & 0.2482
\end{tabular}

The general assumption in this balance sheet is that the sinking fund (total capital, $\$ 9,359,000)$ invested in the first year will be paid back to investors over a 10 year period with a yearly interest rate of $10 \%$. The tax schedule is not included in this calculation since it will have to involve many other related aspects. Further, the sales price of the fossil resin was established in conversations with broker/marketing organizations. The price quoted here actually is the low-end of the price range $(\$ 0.5-0.7 / \mathrm{b})$. 

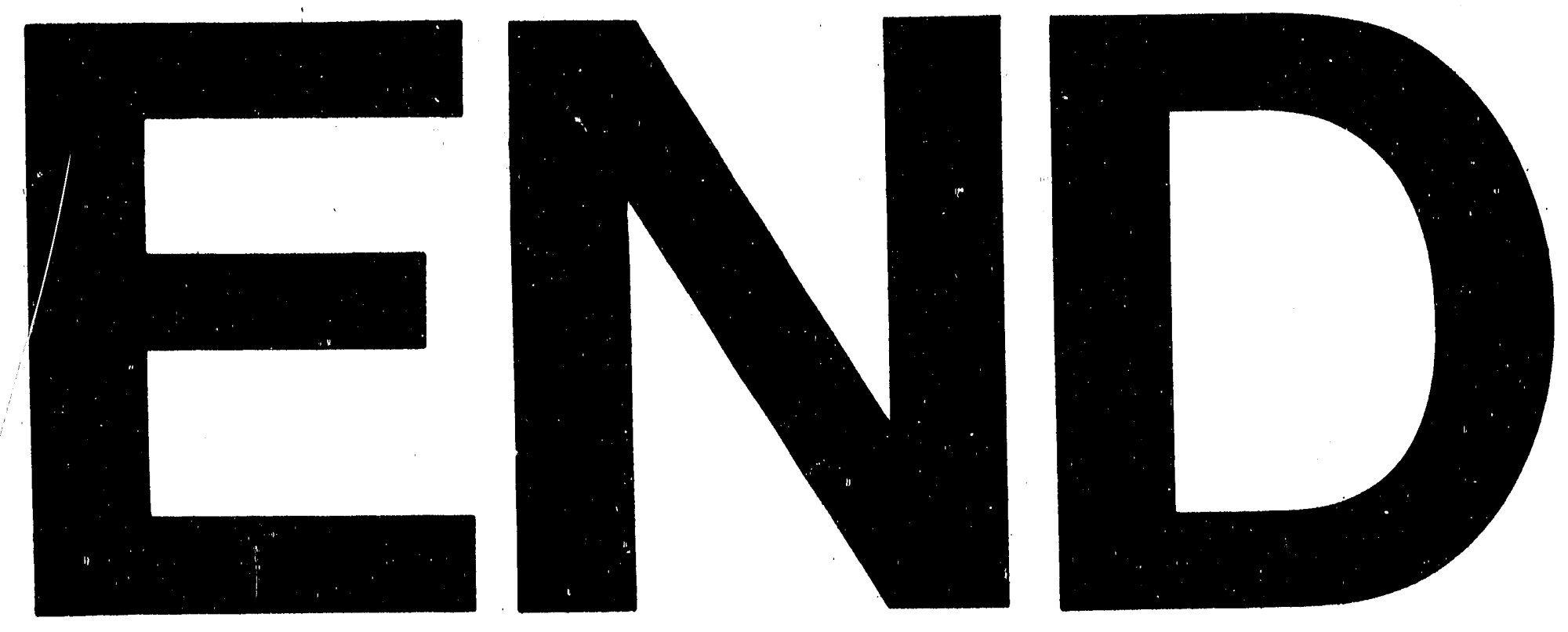

7
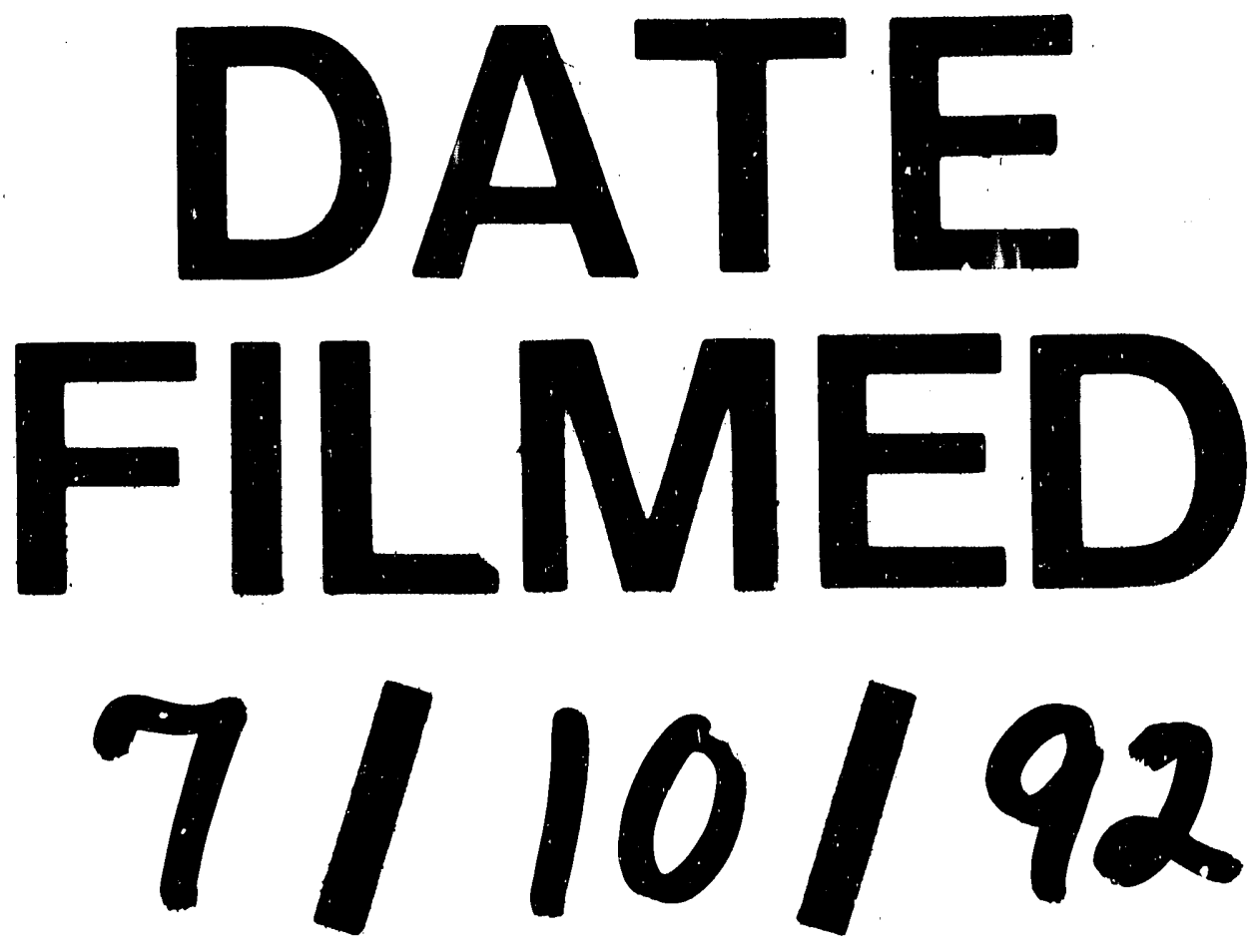
